\title{
Analysis of Job Management Method Oriented by People-Post Matching
}

\author{
Jie Rong \\ Department of Economic and Management, Heze University, No.2269 University Road, Heze, China
}

\begin{abstract}
People-post match is the enterprise management goal and difficulty, this article from the perspective of People-post match, post management of specific methods were analyzed, and the hope of our country enterprise human resources management to provide some constructive Suggestions, to promote the healthy development of China's enterprises.
\end{abstract}

Keywords: People-post match; Post management; On-the-job training; Performance appraisal; Pay back; Position adjustment

\section{Introduction}

In the management of enterprise People-post match is the most desired position management as a result, in order to achieve the business man of the match condition, position in the enterprise management process can adopt the following methods:

\section{Job training oriented by People-post match}

\subsection{Job Knowledge and Skills}

Scope of job responsibilities and to explain his position in the organization,make sure the employees clear the main content of the work and responsibility within the scope, to ensure all jobs in an orderly way. In addition, although the quality of personnel in the process of post configuration already match the job requirements, but in order to make the employees to better understand the nature of jobs and their own should have the quality, need a detailed explanation to the requirement of position, make the employees to better adapt to post requirement, improve the hillock matching degree.

In order to make the staff quickly into the job role, when training needs for the working skills and knowledge system training, employee skills and knowledge to work further understanding and master degree, improve the ability to work.[1]

\subsection{Career Planning}

\subsubsection{Understand the enterprise strategic target}

Staff's career goal is with the aid of enterprise, left the enterprise the carrier, and no employee career development, employee's career planning needs around corporate strategic objectives and formulation. Therefore, the staff career planning, must carry out training education about enterprise strategic target.

In career planning, enterprise strategic objectives and employee career goal is: the relationship between the enterprise strategic objective is the overall goal of all staff career goals, and achieve the goals of each employee career also can promote better realize enterprise strategic objectives.

\subsubsection{Analysis and positioning of its employees}

In order to help employees better understand themselves, enterprises need to staff to conduct a comprehensive analysis, mainly including the demand for employees, goal, quality, character, temperament, interests, skills, values and other aspects of analysis, the enterprise can choose according to situation. Through the comprehensive analysis of employees, can draw for career in the type and level, to help employees to locate himself.

\subsubsection{Environmental analysis}

Enemy and know yourself can ever victorious, not only to make a concrete analysis of individual, also deal with the environment of the employee in a scientific and comprehensive analysis, employee's environmental analysis mainly includes the organizational environment, economic environment and social environment analysis three aspects of content.

\subsubsection{Help employees to develop career planning}

Employee's career goals can be divided into short-term, medium-term and long-term goals: short term goals are usually for one year to two years, short-term goals and refinement for the day, week, month and year of the goal; Medium-term goal is usually three to five years; Long-term goals are usually for five years to ten years, these three goals, respectively, and corresponding to the short-term, medium-term and long-term planning.

In goal setting, the first according to employee's personal situation and the environment determine the long-term goals of employee career development, then long-term goal differentiation, according to the employee's ability to determine the medium-term and short-term goals and organizational development situation. The staff and leadership to discuss its career development goals, and fill in the employee's career clock.

\subsubsection{Career planning evaluation and feedback}

Companies need to regularly to evaluate staff career planning implementation, the development efforts of 


\section{International Journal of Science and Research (IJSR) \\ ISSN (Online): 2319-7064}

Index Copernicus Value (2013): 6.14 | Impact Factor (2014): 5.611

employees, and will assess the results sent to employees. Process according to the assessment results to help employees to be some problems, and put forward the improvement measures of work, and with good performance to give affirmation and praise, lead the staff efforts in the direction of the aim of career planning, finally realizes the employee's career goals. [2]

With the changing of environment factors, some aspects of career planning and career development, there must be not adapt to the situation for this kind of situation, enterprises should change together with the staff career planning after the evaluation of discomfort, to ensure that employees' career success.

\subsection{Enterprise Culture Training}

Training content of enterprise culture can be divided into two aspects: hardware and software on the hardware, can write out the enterprise culture to hang on the wall, on the road signs within an enterprise, in the company any eye-catching place can see the company's corporate culture, employees anytime, anywhere can be the edification of the corporate culture, make the enterprise culture in their mind form a deep impression; In software, in order to explain the meaning of the corporate culture and essence, and the working relationship with them, make them aware of the importance of corporate culture, fully understand your company profoundly the connotation of enterprise culture, and with the staff to the enterprise culture degree of understanding and love, will also actively promote the enterprise image abroad. Can also design some games in the training, make employees participate together, let them feel the enterprise collective strength, and strengthen communication and promote friendship, in the activities to employees working together for common development of the enterprise.

\section{Performance Evaluation and Management Oriented by People-Post Match}

\subsection{Make Work Plan}

First of all, set by the employees of this position work plan, and then, to the immediate superior audit, full communication between the two sides, to determine the final work plan. Working plan includes the following several aspects: [3]

First, The specific work tasks: The daily work in jobs and responsibilities.Second, performance appraisal criteria: must be quantified, from the work task to complete the quantity, quality, use of resources, timeliness and customer evaluation, etc. Third, all tasks weight: according to the importance of the various tasks set weight, weight and is 1.fourth, participate in the evaluators: superior assessments of the participants.

\subsection{Complete the Work Plan}

Direct supervisor of the employee according to the work plan to complete the work, need to timely supervision of work, clearly points out the problem in the working process of the improvement Suggestions were put forward.

\subsection{Work Performance Appraisal}

\subsubsection{Performance Record}

Employees in each job should be to work on time after completed records, fill in the evaluation work tasks, in the process of work is done, if there is a big plan adjustment, the increase or decrease in weight greater than 0.2 work tasks or work task after the weight increase or decrease more than 0.2 ), the evaluation must be filled in to work.

\subsubsection{The Higher Evaluation}

Superior grade on the performance of employees this month degree, grade includes task completion of work and attitude supportive of the two columns, respectively accounted for $80 \%$ and $20 \%$ of the grade.

\subsubsection{Summary of the Achievement}

First of all, according to the task, the content of the evaluation calculation performance record total score. Method to calculate the scores and task for each task is weight multiplied, and the scores of all tasks. Then calculate the final score employee performance. Calculation method for the staff performance record total score and ranking score, determine the final score of performance appraisal.

\subsubsection{Interview}

Supervisor and staff quarters communication task completion and work attitude, discussed in view of the problems arising from the work (for example, a staff's ability to improve or post provided the improvement of the working equipment), formulate the corresponding improvement strategy.

\section{Salary Reward Oriented by People-post match}

\subsection{Determine the Position}

\subsubsection{Divide the Post Grades and Standards}

First of all, the information about the enterprise post and information collection, the main contents include: the name of the post, coding, unit, supervisor unit of jobs and the relationship between higher and lower, job responsibilities, requirements, contents, working conditions and environment. Then, on the basis of widely collecting data, determine the position of the main factors. Then, to evaluate job factors, divided into post level. Finally, according to the different conditions of various factors, the weight of post level under different conditions were determined. [4] 


\section{International Journal of Science and Research (IJSR) \\ ISSN (Online): 2319-7064}

Index Copernicus Value (2013): 6.14 | Impact Factor (2014): 5.611

\subsubsection{Determine the post salary standard}

First of all, to pay market investigation of the position, salary market research main content is: over the past few years the enterprise salary situation of each position, similar enterprises of the same job specific compensation and the enterprise compared with other enterprises of all kinds of personnel salary structure, summary results then, investigating enterprise employee's salary expectations, it is concluded that the post employees expect compensation. Finally, according to the summary results of market investigation and the enterprise staff's salary expectations, determine the enterprise salary standard. General enterprise salary standard is in the region on the industry, the medium level, raise the satisfaction of employees for compensation, increase the competitiveness of the enterprise.

\subsubsection{Computing jobs pay}

Post is multiplied by the standard of weights and remuneration, can calculate the position factor related compensation. [5]

\subsection{Determine the bonus}

In order to improve the staff's work enthusiasm, need to employee bonuses, the bonus amount according to the employee's performance appraisal and determined. First of all, the specific standards for the bonus. Then, according to the above described the calculation method of performance appraisal, employee performance results. Finally, according to the result of performance appraisal, and the standard, it is concluded that the amount of bonus after multiplying.

\subsection{The Payment Summary}

According to the basic pay wages and post salary, seniority wage calculation, and then add those salaries and bonuses, employee compensation.

\subsection{Any Benefit}

Enterprise should according to oneself circumstance, and employee expectations set benefits information. Based on post salary grading setting, the corresponding bonus and performance and welfare, improve employee satisfaction, increase the enthusiasm of the staff, promote employees to consciously improve their own quality, so as to achieve very good incentive effect, better realize the post match.

\section{Position Adjustment Oriented by People-Post Match}

\subsection{Implement Dynamic Post Management.}

Through the staff performance appraisal results, identify scope of selection and promotion, in within the scope of the waiting staff will be given disciplinary action, and then according to the result of the next performance review to determine whether the recovery work, advanced range of personnel in the investigation stage, exploring the various aspects ability is consistent with the requirements of a layer position, management personnel in range given in degraded process directly, thus to promote employees to constantly improve their own quality, achieve even beyond the post requirements of the standard, to implement the dynamic matching of staff quality and post requirements.

\subsection{Management Job Competition}

Implements competition mechanism for management positions, into the advanced range of excellent employees through competition promotion management job, create equal opportunities for staff, make staff to form the consciousness of self improvement, build the atmosphere of a kind of encourage employees to grow, achieve the goal of talent cultivation.

\subsection{Technical Title Evaluation}

Enterprises through title examination, combined with the result of performance appraisal, determine the technical personnel of professional qualification.

\subsection{Establish a Good Staff Training Center}

In order to improve the staff's sense of self improvement, can be in the center of the enterprise to set up the talent training. Do well in the work of employees, the enterprise will be awarded the title of excellent staff and reward, then the enterprise will be training for these employees on a regular basis, learning new skills and knowledge, and open lecture made good staff to introduce their work experience and experience, as the change of employee job performance, constantly adjust the personnel training center. Not only improved the performance outstanding employees' job satisfaction and a sense of pride, and the lagging of employees is a kind of encourage and push. [6]

\section{Acknowledgement}

This paper is the stage research achievements of Heze University's Regional economic and industrial competitiveness Research base.

\section{References}

[1] Zhou Zhu. Human resource management tutorial [M]. Shanghai: Shanghai university of finance and economics press. 2001. 117-126

[2] Zhengzhou Liu. Management incentive [M]. Shanghai: Shanghai university of finance and economics press. 1998:208-212

[3] ChuanHua Yang. How to develop the work plan [M]. Beijing: Peking University press. 2005:30 to 37.

[4] Shuang Wang. State-owned investment company salary system design research [D], wuhan: wuhan university of technology. 2008:34-56

[5] Longsen Yin,Zonghu Sun. Post evaluation and salary system design transaction [M]. Beijing: people's posts and telecommunications publishing house. 2006:53 to 59

[6] Zhi Yang, HanShen Deng. Humanistic management [M] Shandong: university of petroleum press. 1999:217-223

\section{Volume 5 Issue 2, February 2016}

